TP Periodica Polytechnica Mechanical Engineering

62(4), pp. 277-283, 2018

https://doi.org/10.3311/PPme.12117

Creative Commons Attribution (i)

RESEARCH ARTICLE

\section{Grey Relational Analysis and Anova to Determine the Optimum Process Parameters for Friction Stir Welding of Ti and Mg Alloys}

\author{
S. P. Sundar Singh Sivam ${ }^{1 *}$, Krishnaswamy Saravanan ${ }^{2}$, \\ Nagaraj Pradeep ${ }^{2}$, Karuppiah Sathiya Moorthy ${ }^{1}$, \\ Sankarapandian Rajendrakumar ${ }^{1}$ \\ Received 20 February 2018; accepted after revision 15 May 2018
}

\begin{abstract}
The welding of Magnesium and Titanium and its alloys has continuously depicted a good challenge for designers and technologists. Ti and Mg alloys, particularly heat-treatable alloys, are difficult to join by fusion fastening techniques. The welding of dissimilar alloy such as Ti (Grade 2) and Mg (AZ91D) Alloy is an important problem during Friction Stir Welding (FSW). In this paper, the influence of Rotation speed (Rpm), Travel Speed ( $\mathrm{mm} / \mathrm{min})$, Bottom Diameter Tool Pins ( $\mathrm{mm}$ ) and Tool Profiles of Ti and Mg alloy during FSW was investigated by Grey Relational Analysis and Anova was used to work out the foremost important Travel speed and feed rate affecting the Response. The primary and cooperation impact of the information factors on the normal reactions are examined. The expected values and measured values are genuinely close.
\end{abstract}

\section{Keywords}

Mg and Ti alloys, Friction Stir Welding, welding environment

\footnotetext{
${ }^{1}$ Department of Mechanical Engineering, Faculty of Engineering and Technology, SRM Institute of Science and Technology, Kattankulathur - 603203, Tamil Nadu, India

2 Department of Mechatronics Engineering, Faculty of Engineering and Technology, SRM Institute of Science and Technology, Kattankulathur - 603203, Tamil Nadu, India

* Corresponding author, e-mail: sundar.sp@ktr.srmuniv.ac.in
}

\section{Introduction}

Friction Stir Welding (FSW) method could be a solid state change of integrity technique thought of to be the many development over the past twenty years that was fictional and valid at the fastening institute (TWI), UK within the year 1991. That has become a viable producing technology of gilded sheet and plate materials for applications in varied industries, together with region, automobile, defence and building. This change of integrity technique is energy economical, atmosphere friendly and versatile. Above all, it will be wont to be a part of highstrength region aluminium alloys and different gilded alloys that area unit exhausting to weld by standard fusion fastening. During this method a non expendable tool is to be plunged into the surfaces of the plates with rotation and conjointly it moves on the joint line for weld consolidation. The joint integrity depends upon the tool pure mathematics nature utilized in this method. The tools pin and shoulder area units are useful for warmth generation and material mixture by stirring manufacturing the joint. During this method no melting happens and therefore the heat is generated internally by suggests that of friction between the Sheet Metal tool interface and therefore the plastic deformation takes place while not pre heating or post heating. Friction stir fastening, a contemporary associate in an atmosphere friendly solid - state change of integrity method wont to be a part of comparatively lighter family of materials, particularly aluminium and its alloys is dealt during this study [1,2]. Crucial applications of those alloys embrace region, automobile and ship building likewise [3]. The character of the Sheet Metal decides the sort of change of integrity method. Friction stir fastening, that is thought to be as autogenic, hole change of integrity technique fills the void wherever different change of integrity techniques becomes troublesome to implement [4]. Solid-state fastening processes area unit ideally suited to fastening of dissimilar alloys. As a result of these processes doesn't involve melting, the problem of weld action cracking doesn't arise. Similarly, solid-state fastening processes overcome a range of different issues in fusion fastening of aluminium alloys like consistence, segregation, brittle lay to rest gilded formation, and warmth affected zone 
liquation cracking [5]. Aluminium Alloys of two completely different series AA 5052 and AA6061 area unit friction stir welded victimisation specific tool style and using two different optimized welding parameters (constant speed and variable feed). Since fusion fastening of dissimilar aluminium is tedious, Friction Stir Welding (FSW) method is widely used for fastening of dissimilar materials, wherever the formation of secondary part is absent since the temperature concerned during this method is well below the melting temperature of base materials. Previous studies indicate the optimum parameters for fastening of dissimilar atomic number 13 alloys, with rotation speed of 600-1000 rev, traverse speed around $15-40 \mathrm{~mm} / \mathrm{min}$ and $\mathrm{D} / \mathrm{d}$ quantitative relation of $3: 1$ [8]. Higher mechanical properties area unit obtained once tougher material is placed on the advancing facet and softer material in receding facet $[10,12]$. Since tool geometry plays an important role in dissimilar welds, totally different tool profiles are wide getting used of late. Tool pin profiles like rib, square and triangular area units are efficient to transfer the material from high to bottom of the joint and the other way around by stirring action [1020]. Within the Present study, experimental details using the Taguchi technique of parameter style are utilized for optimizing multiple performance characteristics like Rotation Speed (Rpm), travel Speed ( $\mathrm{mm} / \mathrm{min})$, Bottom tool Diameter (mm) and Titling Angle for friction stir fastening (FSW) for dissimilar alloy joints and correlate the results with Mechanical Properties throughout FSW. Relative analysis has been thought about for improvement of multiple response characteristics. Finally analysis of variance (ANOVA) for confirmation take a look at has been conducted to validate the results.

\section{Experimental Procedure}

The material used in this study is $\mathrm{Ti}$ (Grade 2) and $\mathrm{Mg}$ (AZ91D) of plate $100 * 100 * 4 \mathrm{~mm}$, with the following chemical composition (in wt.\%): $0.035 \mathrm{Si}, 0.22 \mathrm{Mn}, 90.8 \mathrm{Mg}, 0.63$ Zn, 8.25 Al, 0.1 C, 0.3 Fe, $1.59 \mathrm{Cu}$, Ti in balance. Mechanical properties of $\mathrm{Ti}$ and $\mathrm{Mg}$ Tensile Strength (Mpa), Yield Strength (Mpa), E (GPa) and Elongation (\%) are 186.42, 132.94, 69 and 9.12 and 208.14, 172.94, 72 and 8.49. TI and $\mathrm{Mg}$ was weld by CNC milling machine LMW (LV45). Specially designed fixture is used to prevent the plates from alignment during welding process. The material which is selected for making tool is SKD61 with the chemical composition (in wt.\%): $0.910 \mathrm{C}, 0.380 \mathrm{Si}$, 0.3 Mn, 0.03 P, 0.005 S, 3.880 Cr, 4.8 Mo, 1.76 V, 6.02 W. The three tools were made from the rod of $20 \mathrm{~mm}$ diameter. The tool have probe diameter of $6,6-4 \mathrm{~mm}$ taper with probe length of $3.8 \mathrm{~mm}$. The shoulder diameter is taken as $18 \mathrm{~mm}$ with cylinder, Step Tapered and Smooth Tapered. Then tool was hardened by flame hardening after hardened the maximum hardness obtained on the Tool is $57 \mathrm{HRB}$ at $150 \mathrm{kgf}$ load with ball indenter.

The two dissimilar plates to be welded are clamped rigidly into the specially designed fixture to prevent the plates from alignment during welding process. The strip is to be positioned into the fixture by placing strip $\mathrm{Ti}$ and $\mathrm{Mg}$ on advancing side and on retreating side. The tool is to be fitted into the spindle and the offset of sample to the tool is taken. The cylindrical pin profile tool is fitted to the VMC. The tool is slowly plunged into the work piece until the shoulder contacts the surface of the work piece. A small downward force is applied to maintain the contact and it is kept for few seconds for producing heat. Then the tool is forced forward over the weld length of $130 \mathrm{~mm}$ of the work piece. The welding process is shown in Fig. 1. After it reaches the end point the tool is retarded from the workpiece leaving a hole at the end. The hole is produced because of the tool pin. These are done automatically by the machine after the required parameters were given. The hardened fabricated tool was in Fig. 2.

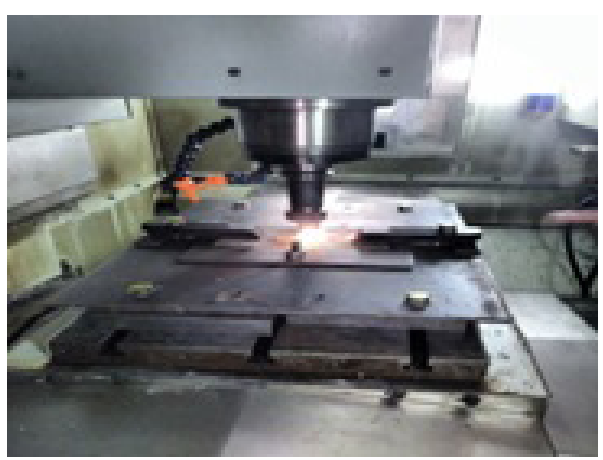

Fig. 1 Experimental Setup

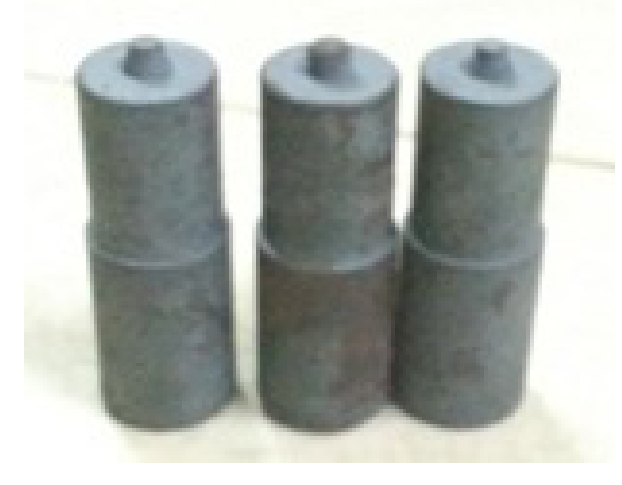

Fig. 2 Tool after Hardening

\section{Methods of analysis}

Analysis of variance (ANOVA) with Taguchi technique as in could be a statistical procedure won't to interpret experimental knowledge. During this study, there are four primary controllable factors, i.e. three levels such as rotation speed $(1000 / 1500 / 2000 \mathrm{rpm})$, travel speed $(90 / 150 / 210 \mathrm{~mm} / \mathrm{min})$, Bottom Diameter Tool Pin (6/7/8), and Tool Design (cylinder / Step Tapered / Smooth Tapered), which are used for ANOVA. Their interactions may be computed from the experimental information through multivariate analysis. During this study, using Taguchi techniques, the $\mathrm{L}_{9}$ orthogonal arrays are needed for Tensile Strength (Mpa), Yield Strength (Mpa), Shear 
Strength (GPa) and Elongation (\%). Total degrees of freedom may be calculated as [16]. Based on Taguchi's recommendation within the larger the $\mathrm{S} / \mathrm{N}$ ratio for ultimate tensile strength and elongation rate is the better [13].

The transformation of $\mathrm{S}-\mathrm{N}$ ratio values from the Experimental response values was the initial step. For that the Eq. (1) of "larger the better" was used. Ensuant analysis was carried out on the premise of these $\mathrm{S} / \mathrm{N}$ ratio values. This can be shown in Table 3.

$$
S / N=-10 \log _{10}\left(\frac{1}{n} \sum_{i=r}^{n} \frac{1}{y_{i j}^{2}}\right) .
$$

In GRA, initially the experimental knowledge is normalized. By using this normalized data, relational coefficient are evaluated, the Grey relational grade was obtained by averaging the GRC values related to selected experimental results.

GRG may be classified into 4 sorts particularly Smaller the better, Larger the better or Nominal could be a better (NB) criterion. The preferred quality characteristics for Final Tensile Strength, Yield Strength, Elongation and Young's Modulus are Larger the better criterion, and then it's expressed by using Eq. (2):

$$
y_{i}^{*}(k)=\frac{y_{i}(k)-\min y_{i}(k)}{\max y_{i}(k)-\min y_{i}(k)} .
$$

Where $i=1, \ldots m ; k=1,2,3, \ldots n ; m=$ no. of experimental data; $n=$ no. of factors; $y_{i}(k)=$ original sequence; $y_{i}^{*}(k)$ value after Grey relational generation; $\min y_{i}(k)$ and $\max y_{i}(k)$ are the minimum and maximum value of $y_{i}(k)$, respectively. The normalized values are shown in Table 3. The calculation for Grey relation coefficient was done using Eq. (3).

$$
\varepsilon_{i}(k)=\frac{\Delta \min +\omega \Delta \max }{\Delta_{o i}(k)+\omega \Delta \max } .
$$

Where $\varepsilon_{i}(k)$ is the Grey relation coefficient; $\Delta_{o i}$ is deviation among $y_{o}{ }^{*}(k)$ and $y_{i}{ }^{*}(k) ; y_{o}{ }^{*}(k)=$ ideal (reference) sequence; $\Delta \max =$ highest value of $\Delta_{o i}(k), \Delta \min =$ least value of $\Delta_{o i}(k)$.

The Grey relational grades (GRG) $\left(\Gamma_{i}\right)$ are determined by taking average of the GR coefficient related to every observation as given in Eq. (4), Table 3 and Fig. 6:

$$
\Gamma_{i}=\frac{1}{n} \sum_{i=1}^{Q}(k) .
$$

Where, $Q=$ total quantity of responses and $\mathrm{n}$ denotes the quantity of output responses. The GRG $\Gamma_{i}$ represents level of relationship among the reference or ideal sequence and the comparative sequence. If larger GRG is obtained for the equivalent set of process parameters compared to other sets, it's considered as the most favourable optimum setting.

The selection of process parameter is the main factor in the Friction Stir Welding. The rotation of tool results in stirring and mixing of material around the rotating pin and the translation of tool moves the stirring and mixing of the material from the front to the back of the pin and finishes welding process. Hence the process parameters which are used to weld the flats and the good strength of the specimen can be obtained based on the welding parameters. The process parameters are listed in Table 1.

Table 1 Process parameter Design

\begin{tabular}{lcccc}
\hline & Unit & \multicolumn{3}{c}{ Levels } \\
\cline { 3 - 5 } Parameters & Rpm & 1000 & 1500 & 2000 \\
\hline $\begin{array}{l}\text { Rotation } \\
\text { Speed } \\
\text { Travel } \\
\text { Speed }\end{array}$ & mmin & 90 & 150 & 210 \\
$\begin{array}{l}\text { Bottom } \\
\text { Diameter }\end{array}$ & mm & 6 & 7 & 8 \\
Tool Design & shape & cylinder & Step Tapered & $\begin{array}{l}\text { Smooth } \\
\text { Tapered }\end{array}$ \\
\hline
\end{tabular}

The process for welding of dissimilar Ti and Mg alloys in Fig. 3. Here the strip is to be positioned into the fixture by placing strip Ti on advancing side and strip $\mathrm{Mg}$ on retreating side. The same principle is carried out for the welding process after it reaches the end point the tool is retracted from the workpiece.

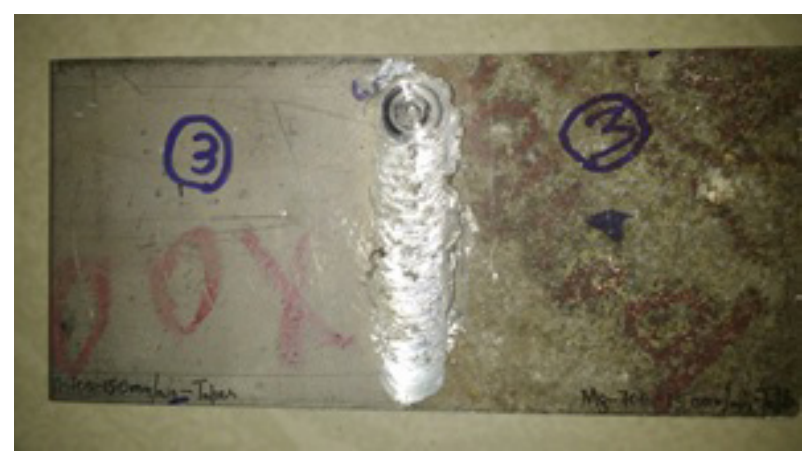

Fig. 3 Welded Samples of Dissimilar Alloys

\section{Results and discussion}

The material test is made by gripping the ends of a suitably prepared standardized test piece in a tensile test machine and then applying a continually increasing uni-axial load until such time as failure occurs. After the welding process the transverse tensile specimen are prepared with reference to ASTM E8M Standard and the specimens' geometry and dimensions shown in Fig. 4 and 5.

From Table 4, it is found that Tensile Strength is the major factor affecting the Travel Speed (74.07 \%) followed by Tool Design (18.21\%), Bottom Diameter (6.71\%) and Rotation Speed (1.02 \%). In Table 6, Elongation is found to be the most significant factors affecting the Rotation Speed (50.00 ) followed by Tool Design (22.07 \%), Bottom Diameter (19.37\%), and Travel Speed (8.6\%). In Table 7, Shear Strength is found to be the most significant factors affecting the Travel Speed (68.69 \%) followed by Rotation Speed (16.32\%), Bottom Diameter and Tool Design (7.5\%). In Table 8, Grey Grade is 


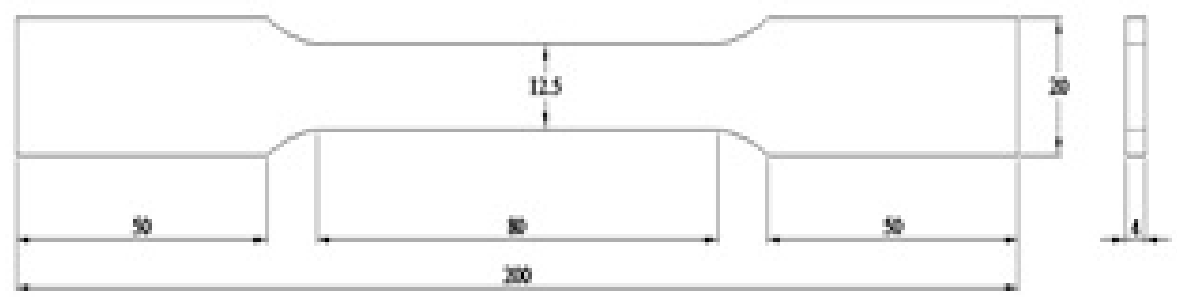

Fig. 4 Tensile Specimen with ASTM E8M
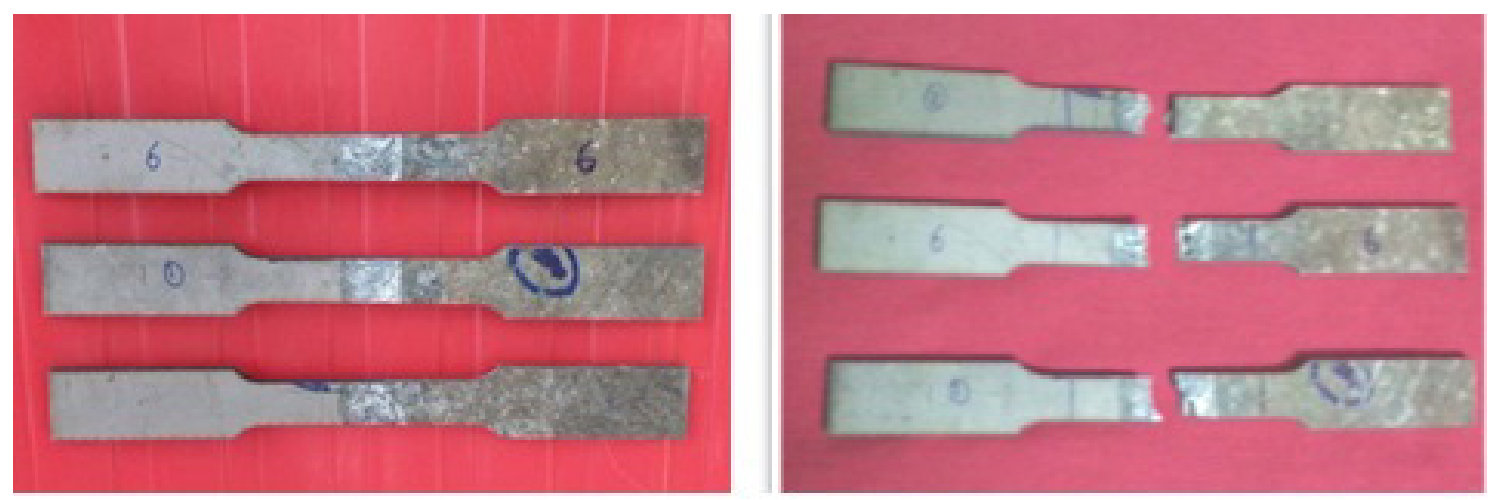

Fig. 5 Tensile Specimen of Dissimilar Alloys

Table 2 The FSW Process data of $\mathrm{L}_{9}$ orthogonal arrays

\begin{tabular}{|c|c|c|c|c|c|c|c|c|}
\hline \multirow[b]{2}{*}{ Trial No. } & \multirow{2}{*}{$\begin{array}{c}\text { Rotation } \\
\text { Speed (Rpm) }\end{array}$} & \multirow{2}{*}{$\begin{array}{c}\text { Travel Speed } \\
(\mathrm{mm} / \mathrm{min})\end{array}$} & \multirow{2}{*}{$\begin{array}{c}\text { Bottom } \\
\text { Diameter Tool } \\
(\mathrm{mm})\end{array}$} & \multirow{2}{*}{$\begin{array}{c}\text { Tool } \\
\text { Design }\end{array}$} & \multicolumn{4}{|c|}{ FSW PROCESS RESPONSE } \\
\hline & & & & & $\begin{array}{c}\text { Tensile Strength } \\
\text { (Мра) }\end{array}$ & $\begin{array}{c}\text { Yield Strength } \\
\text { (Мра) }\end{array}$ & $\begin{array}{c}\text { Shear Strength } \\
\text { (GPa) }\end{array}$ & $\begin{array}{c}\text { Elongation } \\
(\% \text { in } 50 \mathrm{~mm})\end{array}$ \\
\hline 1 & 1000 & 90 & 6 & 1 & 360 & 240 & 290 & 4.4 \\
\hline 2 & 1000 & 150 & 7 & 2 & 345 & 234 & 278 & 4.1 \\
\hline 3 & 1000 & 210 & 8 & 3 & 320 & 228 & 270 & 3.9 \\
\hline 4 & 1500 & 90 & 6 & 1 & 348 & 265 & 280 & 3.0 \\
\hline 5 & 1500 & 150 & 7 & 2 & 340 & 220 & 274 & 3.9 \\
\hline 6 & 1500 & 210 & 8 & 3 & 329 & 218 & 260 & 3.4 \\
\hline 7 & 2000 & 90 & 6 & 1 & 350 & 280 & 296 & 4.2 \\
\hline 8 & 2000 & 150 & 7 & 2 & 335 & 210 & 270 & 3.7 \\
\hline 9 & 2000 & 210 & 8 & 3 & 338 & 220 & 276 & 3.6 \\
\hline
\end{tabular}

Table 3 FSW Response Data with Normalized, Grey relational and Grey Grade

\begin{tabular}{|c|c|c|c|c|c|c|c|c|c|}
\hline \multicolumn{4}{|c|}{ Normalized $\mathrm{S} / \mathrm{N}$ ratio } & \multicolumn{4}{|c|}{ Grey Relational Coefficient } & \multicolumn{2}{|c|}{ Grey } \\
\hline 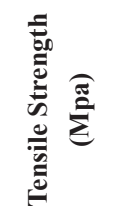 & 营 & 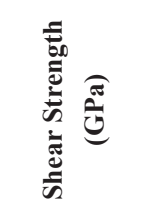 & 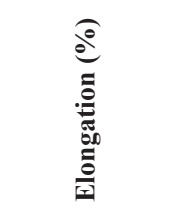 & 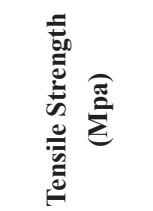 & 缹 & 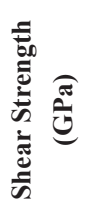 & 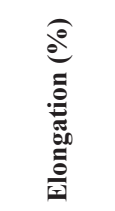 & : & \\
\hline 0.00045 & 0.441404 & 0.06367906 & 0.903999204 & 0.33333333 & 0.472324 & 0.348 & 0.99399 & 0.538442 & 4 \\
\hline 0.613914 & 0.159669 & 0.09039992 & 0.36900021 & 0.56427983 & 0.373042 & 0.333 & 0.44208 & 0.428186 & 7 \\
\hline 0.945886 & 0.090399 & 0.03698927 & 0.090399920 & 0.90234272 & 0.333333 & 0.341 & 0.33333 & 0.477693 & 5 \\
\hline 0.663506 & 0.200059 & 0.07601753 & 0.090399920 & 0.59773321 & 0.384633 & 0.351 & 0.33333 & 0.416707 & 8 \\
\hline 0.407817 & 0.337246 & 0.00135932 & 0.090399920 & 0.45779914 & 0.430013 & 0.333 & 0.33333 & 0.388695 & 9 \\
\hline 0.888127 & 0.903999 & 0.03698927 & 0.090399920 & 0.81716329 & 0.903999 & 0.341 & 0.33333 & 0.623064 & 3 \\
\hline 0.788943 & 0.258456 & 0.03698927 & 0.36900021 & 0.70317948 & 0.402724 & 0.341 & 0.44208 & 0.472438 & 6 \\
\hline 0.903999 & 0.903999 & 0.14783510 & 0.36900021 & 0.90399920 & 0.838925 & 0.369 & 0.44208 & 0.662697 & 2 \\
\hline 0.608226 & 0.599880 & 0.09039992 & 0.090399920 & 0.56068040 & 0.555481 & 0.993 & 0.99399 & 0.779041 & 1 \\
\hline
\end{tabular}


Table 4 ANOVA for Tensile Strength

\begin{tabular}{|c|c|c|c|c|c|c|}
\hline Source of variation & Sum of Squares & DOF & Mean Square & $\mathbf{F}$ & F table & Contribution $\%$ \\
\hline Rotation Speed & 11.5556 & 2 & 5.7778 & 28888.89 & 4.2 & 1.02 \\
\hline Travel Speed & 841.5556 & 2 & 420.7778 & 2103888 & 4.2 & 74.07 \\
\hline Bottom Diameter Tool & 76.2222 & 2 & 38.1111 & 190555.5 & 4.2 & 6.71 \\
\hline Tool Design & 206.8889 & 2 & 103.4444 & 517222.2 & 4.2 & 18.21 \\
\hline Error & 0.002 & 9 & 0.000200 & & & \\
\hline SST & 1136.2222 & 17 & & & 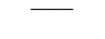 & \\
\hline
\end{tabular}

Table 5 ANOVA for yield Strength

\begin{tabular}{|c|c|c|c|c|c|c|}
\hline Source of variation & Sum of Squares & DOF & Mean Square & $\mathbf{F}$ & F table & Contribution $\%$ \\
\hline Rotation Speed & 12.6667 & 2 & 6.3333 & 31666.67 & 4.2 & 0.29 \\
\hline Travel Speed & 3200.6667 & 2 & 1600.3333 & 8001666.67 & 4.2 & 73.34 \\
\hline Bottom Diameter Tool & 698.0000 & 2 & 349.0000 & 1745000.00 & 4.2 & 15.99 \\
\hline Tool Design & 452.6667 & 2 & 226.3333 & 1131666.67 & 4.2 & 10.37 \\
\hline Error & 0.002 & 9 & 0.000200 & & & \\
\hline SST & 4364.0000 & 17 & & & 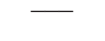 & \\
\hline
\end{tabular}

Table 6 ANOVA for Elongation

\begin{tabular}{|c|c|c|c|c|c|c|}
\hline Source of variation & Sum of Squares & DOF & Mean Square & $\mathbf{F}$ & F table & Contribution \% \\
\hline Rotation Speed & 0.7400 & 2 & 0.3700 & 1850.00 & 4.2 & 50.00 \\
\hline Travel Speed & 0.1267 & 2 & 0.0633 & 316.67 & 4.2 & 8.56 \\
\hline Bottom Diameter Tool & 0.2867 & 2 & 0.1433 & 716.67 & 4.2 & 19.37 \\
\hline Tool Design & 0.3267 & 2 & 0.1633 & 816.67 & 4.2 & 22.07 \\
\hline Error & 0.002 & 9 & 0.000200 & & & \\
\hline SST & 1.4800 & 17 & & & - & \\
\hline
\end{tabular}

Table 7 ANOVA for Shear Strength

\begin{tabular}{|c|c|c|c|c|c|c|}
\hline Source of variation & Sum of Squares & DOF & Mean Square & $\mathbf{F}$ & F table & Contribution \% \\
\hline Rotation Speed & 152.8889 & 2 & 76.4444 & 382222.22 & 4.2 & 16.32 \\
\hline Travel Speed & 643.5556 & 2 & 321.7778 & 1608888.89 & 4.2 & 68.69 \\
\hline Bottom Diameter Tool & 70.2222 & 2 & 35.1111 & 175555.56 & 4.2 & 7.50 \\
\hline Tool Design & 70.2222 & 2 & 35.1111 & 175555.56 & 4.2 & 7.50 \\
\hline Error & 0.002 & 9 & 0.000200 & & & \\
\hline SST & 936.8889 & 17 & & & - & \\
\hline
\end{tabular}

Table 8 ANOVA for Grey Grade

\begin{tabular}{|c|c|c|c|c|c|c|}
\hline Source of variation & Sum of Squares & DOF & Mean Square & $\mathbf{F}$ & F table & Contribution $\%$ \\
\hline Rotation Speed & 0.0508 & 2 & 0.0254 & 126.92 & 4.2 & 36.91 \\
\hline Travel Speed & 0.0408 & 2 & 0.0204 & 102.05 & 4.2 & 29.68 \\
\hline Bottom Diameter Tool & 0.0397 & 2 & 0.0198 & 99.16 & 4.2 & 28.84 \\
\hline Tool Design & 0.0063 & 2 & 0.0031 & 15.73 & 4.2 & 4.58 \\
\hline Error & 0.002 & 9 & 0.000200 & & & \\
\hline SST & 0.1375 & 17 & & & 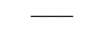 & \\
\hline
\end{tabular}

found to be the most significant factors affecting the Rotation Speed (36.91\%) followed by Travel Speed (29.68\%), Bottom Diameter $(28.84 \%)$ and Tool Design $(4.58 \%)$. The degree of importance of each parameter is considered, namely, Tensile Strength (Mpa), Yield Strength (Mpa), Young's Modulus (GPa) and Elongation (\%) of weld for each response is given in Tables 4-8, respectively and Grey Grade.

From Fig. 6, it can be inferred that, Rotation Speed of 2000 Rpm, Travel Speed of $90 \mathrm{~mm} / \mathrm{min}$, Bottom Diameter of Tool Radius of $7 \mathrm{~mm}$ and Tool Design cylindrical are 
most optimum conditions for obtaining Maximum Tensile Strength. From Fig. 7, it can be inferred that, Rotation Speed of 2000 Rpm, Travel Speed of 90 mm/min, Bottom Diameter of Tool Radius of $8 \mathrm{~mm}$ and Tool Design step Tapered are most optimum conditions for obtaining Maximum Yield Strength. From Fig. 8, it can be inferred that, Rotation Speed of $1000 \mathrm{Rpm}$, Travel Speed of $150 \mathrm{~mm} / \mathrm{min}$, Bottom Diameter of Tool Radius of $8 \mathrm{~mm}$ and Tool Design cylindrical are most optimum conditions for obtaining Maximum Elongation. From Fig. 9, it can be inferred that, Rotation Speed of 2000 Rpm, Travel Speed of $90 \mathrm{~mm} / \mathrm{min}$, Bottom Diameter of Tool Radius of $8 \mathrm{~mm}$ and Tool Design cylindrical are most optimum conditions for obtaining Maximum Shear Strength. From Fig. 10, it can be inferred that, Rotation Speed of 2000 Rpm, Travel Speed of $210 \mathrm{~mm} / \mathrm{min}$, Bottom Diameter of Tool Radius of $6 \mathrm{~mm}$ and Tool Design cylindrical are most optimum conditions for obtaining the Grade Values.

\section{Conclusion}

Friction Stir Welding has immensely high potential in the field of thermo mechanical processing of various alloys especially the Ti and Mg alloys. The Friction Stir Welding of dissimilar alloys of Ti (Grade 2) and Mg (AZ91D) is successfully fabricated using CNC vertical milling machine. The influence

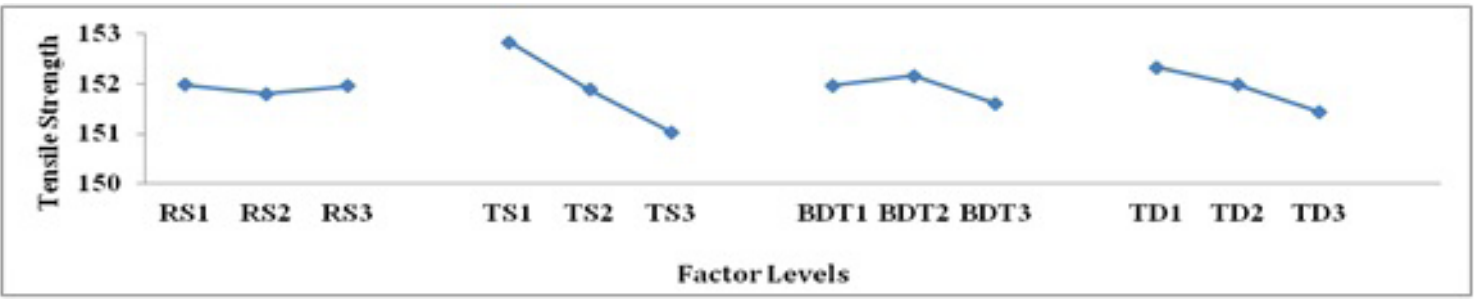

Fig. 6 Factor Effects on Tensile Strength

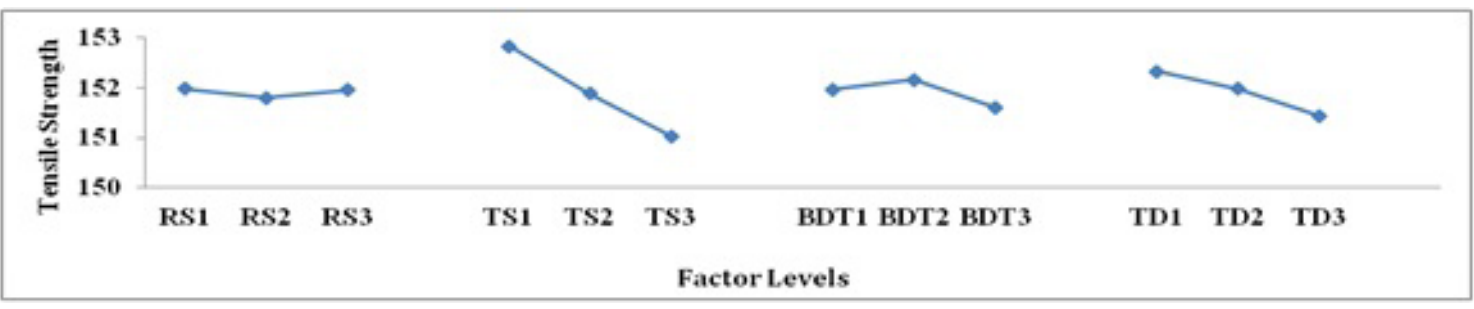

Fig. 7 Factor Effects on Yield Strength

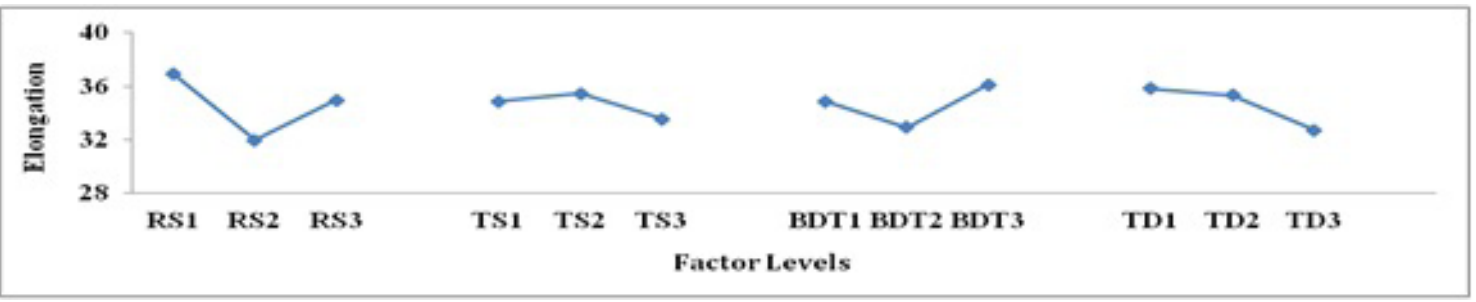

Fig. 8 Factor Effects on Elongation

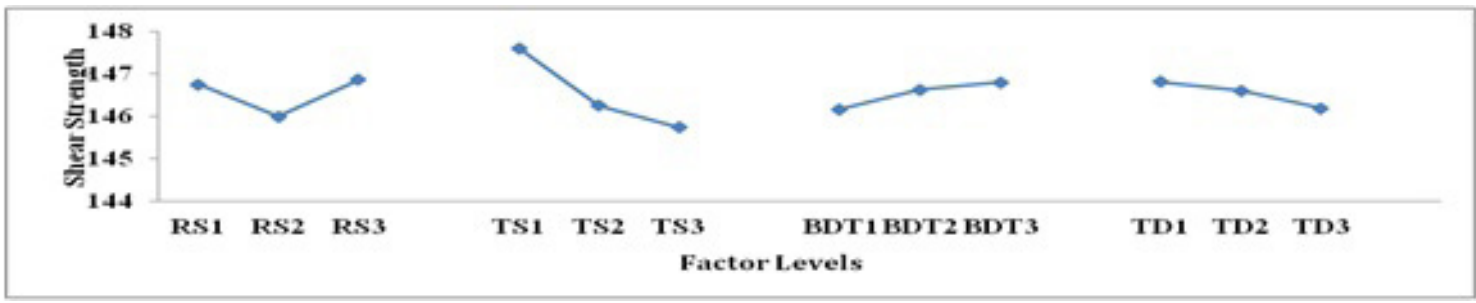

Fig. 9 Factor Effects on Shear Strength

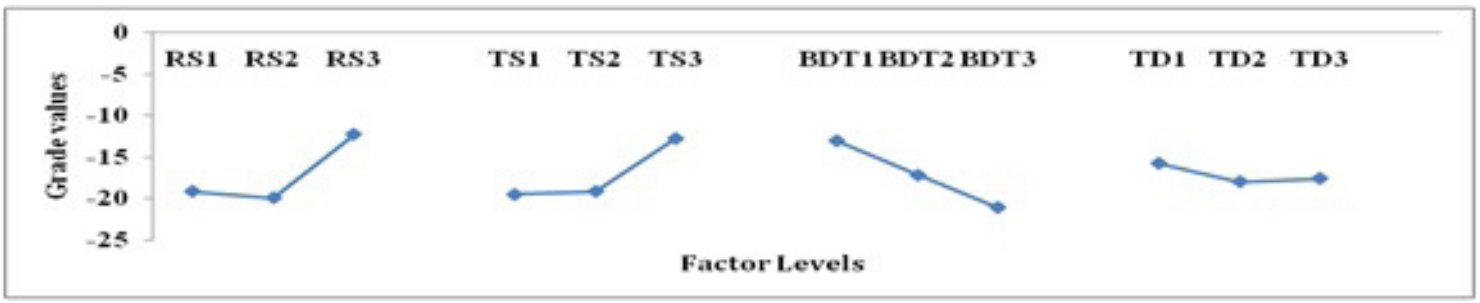

Fig. 10 Factor Effects on Grade values 
of each process parameters on final weld quality related to mechanical properties have been made to determine its potential and limitations. The most significant FSW process parameter listed here. For the Tensile Strength is the Travel Speed (74.07 \%), for the Yield Strength the Travel Speed (73.34\%), for the Elongation is the Rotation Speed (50.00\%), for the Shear Strength the Travel Speed $(68.69 \%)$ and for the Grey Grade is the Rotation Speed (36.91 \%). The best optimum parameter will be RS3, TS3, BDT1 and TD1.

\section{References}

[1] Mishra, R. S., Ma, Z. Y. "Friction stir welding and processing." Materials Science and Engineering: R: Reports. 50(1-2), pp. 1-78. 2005. https://doi.org/10.1016/j.mser.2005.07.001

[2] Shigematsu, I., Kwon, Y.-J., Suzuki, K., Imai, T., Saito, N. "Joining of 5083 and 6061 aluminum alloys by friction stir welding." Journal of Materials Science Letters. 22(5), pp. 353-356. 2003.

[3] Dawes, C. J., Thomas, W. M. "Friction stir process welds aluminium alloys." Welding Journal. 75(3), pp. 41-45. 1996.

[4] Thomas, W. M., Nicholas, E. D. "Frictions stir welding for the transportation industries." Materials \& Design. 18(4-6), pp. 269-273. 1997. https://doi.org/10.1016/S0261-3069(97)00062-9

[5] Kumbhar, N. T., Sahoo, S. K., Samajdar, I., Dey, G. K., Bhanumurthy, K. "Microstructure and microtextural studies of friction stir welded aluminium alloy 5052." Materials \& Design. 32(3), pp. 1657-1666. 2011. https://doi.org/10.1016/j.matdes.2010.10.010

[6] Mahabunphachai, S., Koç, M. "Investigations on forming of aluminum 5052 and 6061 sheet alloys at warm temperatures." Materials \& Design. 31(5), pp. 2422-2434. 2010.

https://doi.org/10.1016/j.matdes.2009.11.053

[7] ASTM E8/E8M - 09, "Standard Test Methods for Tension Testing of Metallic Materials." ASTM International, West Conchocken, Pennsylvania, USA, 2009.

[8] Koilraj, M., Sundareswaran, V., Vijayan, S., Koteswara Rao, S. R. "Friction stir welding of dissimilar aluminum alloys AA2219 to AA5083 Optimization of process parameters using Taguchi technique." Materials \& Design. 42, pp. 1-7. 2012. https://doi.org/10.1016/j.matdes.2012.02.016

[9] Sato, Y. S., Urata, M., Kokawa, H., Ikeda, K. "Hall-Petch relationship in friction stir welds of equal channel angular-pressed aluminium alloys." Material Science and Engineering:A. 354(1-2), pp. 298-305. 2003. https://doi.org/10.1016/S0921-5093(03)00008-X

[10] Xue, P., Ni, D. R., Wang, D., Xiao, B. L., Ma, Z. Y. "Effect of friction stir welding parameters on the microstructure and mechanical properties of the dissimilar Al-Cu joints." Materials Science and Engineering: A. 528(13-14), pp. 4683-4689. 2011. https://doi.org/10.1016/j.msea.2011.02.067
[11] Padmanaban, G., Balasubramanian, V. "Selection of FSW tool pin profile, shoulder diameter and material for joining AZ31B magnesium alloy An experimental approach." Materials \& Design. 30(7), pp. 2647-2656. 2009

https://doi.org/10.1016/j.matdes.2008.10.021

[12] Kwon, Y. J., Shigematsu, I., Saito, N. "Dissimilar friction stir welding between magnesium and aluminum alloys." Materials Letters. 62(23), pp. 3827-3829. 2008.

[13] Logothetis, N. "Managing for Total Quality: From Deming to Taguchi and SPC." Prentice Hall, Englewood Cliffs, New Jersey, USA. 1992.

[14] Chien, C.-H., Lin, W.-B., Chen, T. "Optimal FSW process parameters for aluminum alloys AA5083." Journal of the Chinese Institute of Engineers. 34(1), pp. 99-105. 2011. https://doi.org/10.1080/02533839.2011.553024

[15] Sivam, S. P. S. S., Gopal, M., Venkatasamy, S., Singh, S. "An Experimental Investigation and Optimisation of Ecological Machining Parameters on Aluminium 6063 in its Annealed and Unannealed Form." Journal of Chemical and Pharmaceutical Sciences. 9(Special Issue), pp. 46-53. 2015.

[16] Sivam, S. P. S. S., Gopal, M., Venkatasamy, S., Singh, S. "Application of Forming Limit Diagram and Yield Surface Diagram to Study Anisotropic Mechanical Properties of Annealed and Unannealed SPRC 440E Steels." Journal of Chemical and Pharmaceutical Sciences. 9(Special Issue), pp. 15-22. 2015.

[17] Sivam, S. P. S. S., Lakshman Kumar, A., Sathiya Moorthy, K., Kumar, R. "Investigation Exploration Outcome of Heat Treatment on Corrosion Resistance of AA 5083 in Marine Application." International Journal of Chemical Sciences. 14(S2), pp. 453-460. 2016.

[18] Sivam, S. P. S. S., Uma Sekar, V. G., Mishra, A., Mondal, A., Mishra, S. "Orbital Cold Forming Technology - Combining High Quality Forming with Cost Effectiveness - A Review." Indian Journal of Science and Technology. 9(38), pp. 1-7. 2016.

https://doi.org/10.17485/ijst/2016/v9i38/91426

[19] Sivam, S. P. S. S., Uma Sekar, V. G., Saravanan, K., RajendraKumar, S., Karthikeyan, P., Sathiya Moorthy, K. "Frequently used Anisotropic Yield Criteria for Sheet Metal Applications: A Review." Indian Journal of Science and Technology. 9(47), 2016. https://doi.org/10.17485/ijst/2015/v8i1/92107

[20] Sivam, S. P. S. S., Karuppaiah, S. M., Yedida, B. K., Atluri, J. R., Mathur, S. "Multi Response Optimization of Setting Input Variables for Getting Better Product Quality in Machining of Magnesium AM60 by Grey Relation Analysis and ANOVA." Periodica Polytechnica Mechanical Engineering. 62(2), pp. 118-125. 2018. https://doi.org/10.3311/PPme.11034 